\title{
A polycentric approach for pandemic governance: nested externalities and co-production challenges
}

\author{
Pablo Paniagua ${ }^{1,2 \star}$ (D) and Veeshan Rayamajhee ${ }^{3}$ \\ ${ }^{1}$ Centre for the Study of Governance and Society, King's College London, London, UK, ${ }^{2}$ Senior Researcher at Fundación Para \\ el Progreso, Chile and ${ }^{3}$ Department of Agribusiness and Applied Economics, North Dakota State University, Fargo, \\ North Dakota \\ ${ }^{\star}$ Corresponding author. Email: pablo.paniagua_prieto@kcl.ac.uk
}

(Received 9 June 2021; revised 25 October 2021; accepted 26 October 2021; first published online 18 November 2021)

\begin{abstract}
Political economists assume that global externalities, such as pandemics and climate change, require global or multi-national solutions. Yet, many aspects of these externalities can be addressed at the micro-level. As Elinor Ostrom pointed out, what scholars perceive as global externalities are in fact nested externalities that are organized in multiple, overlapping scales. By drawing on Ostrom's oeuvre, we explore the notions of nested externalities, polycentricity, and co-production in the context of pandemic governance. We highlight two crucial features of pandemics: first, preventative measures such as social distancing are co-production processes that cannot be provided by governments alone. Second, pandemics, much like climate change, pose nested externalities problems at different levels. Thus, pandemic externalities are better viewed as collective action problems arranged at multiple, nested, and/or overlapping scales. Finally, we propose an alternative institutional take that considers the nestedness of pandemic externalities and the diversity in institutional conditions across jurisdictions.
\end{abstract}

Key words: Co-production; Elinor Ostrom; externalities; institutional diversity; polycentricity

JEL Codes: H4; O3; Q2; Q5; Q54; Z1

\section{Introduction}

Sixty years ago, Ostrom, Tiebout, and Warren (1961) (OTW) challenged the dominant view that a multiplicity of governmental units was 'pathological' and that some form of 'gargantua' was needed to reduce duplication, improve governance, and increase efficiency in public goods delivery (Ostrom et al., 1961). OTW's work motivated decades of investigations by scholars associated with the Bloomington school of political economy, most notably by Elinor Ostrom and her colleagues, that extended beyond metropolitan governance and encompassed common pool resources, police services, disaster management, and global climate change (Hodgson, 2013; Ostrom, 1990, 2010a, 2012; Ostrom et al., 1978; Rayamajhee, 2020; Rayamajhee and Paniagua, 2021; Thiel et al., 2019). ${ }^{1}$ These studies overwhelming show that diverse and complex patterns of organizations are not pathological simply because they do not match the scholarly expectations regarding processes and outcomes. Collective challenges we face in the real world are diverse: even the same collective action problem takes on a variety of forms based on the existing institutions and geographical constraints (Ostrom, 1990; Rayamajhee and Paniagua, 2021). Individuals and societies regularly devise new institutions

\footnotetext{
${ }^{1}$ For an overview of the character and impact of Elinor Ostrom's work, see the introductory essay by Hodgson (2013) and the other papers in the Ostrom Memorial Issue.

(c) The Author(s), 2021. Published by Cambridge University Press on behalf of Millennium Economics Ltd. This is an Open Access article, distributed under the terms of the Creative Commons Attribution licence (https://creativecommons.org/licenses/by/4.0/), which permits unrestricted re-use, distribution, and reproduction in any medium, provided the original work is properly cited.
} 
and modify existing ones to tackle the messy challenges of the real world. No single form of organization can be optimal simply because it fits the criteria established by an outsider analyst (Ostrom and Parks, 1999; Rayamajhee and Paniagua, 2021).

The presumption that the existence of multiple decision-making authorities and overlapping roles is pathological undergirds most of current public health policy analyses. Public health and infectious disease control, it is argued, are 'global public goods' because the costs of disease spread and the benefits of prevention have global spillover effects with little possibility to geographically constrain them (Brown and Susskind, 2020; Woodward and Smith, 2003). Global cooperation from national governments and a unified worldwide effort are often seen as the only paths to ending a pandemic (UN News, 2020). Moreover, such analyses overlook the roles of informal institutions such as culture and social relations in influencing societal response to both the pandemic and formal governmental restrictions (Bentkowska, 2021; Rayamajhee, 2020; Rayamajhee and Paniagua, 2021). Since pandemics present large-scale externalities, policy analysts tend to treat pandemic challenges as homogenous problems to be solved at a national or global level, disregarding institutional diversity and heterogeneity of challenges. Evaluations of successes and failures tend to overemphasize the role of national governments and international organizations, with a minimal recognition of the role of non-state actors and sub-national governmental actors.

Most epidemiologists and economists model pandemic response from the perspective of a unitary social health planner, solely responsible for internalizing public health externalities (Alvarez et al., 2020; Gersovitz, 2011; Gersovitz and Hammer, 2004). These models assume that central governments are the only relevant actors in pandemic policy design and implementation. Where the roles of nonstate actors are considered, they are typically viewed as passive responders of government policies. Only a handful of studies pay attention to the proactive role of non-state actors (Bentkowska, 2021; Rayamajhee, 2020; Rayamajhee et al., 2021; Storr et al., 2021) or sub-national (e.g. state and local) governmental actors (Choutagunta et al., 2021) in pandemic response.

This paper presents an alternative take that views pandemic and viral externalities as nested collective action problems of varying scales arranged within multiple interdependent and/or overlapping levels. Within each level and across different levels, various mid- to large-scale efforts from private, public, and non-governmental actors are critical in solving collective challenges. These efforts include devising new institutions as well as adapting existing ones to tackle new changing challenges. As the works of Elinor Ostrom $(2009,2012)$ show, global externalities and large-scale collective action problems such as climate change are better framed as nested externalities. Our first contribution is to extend the Ostromian logic of externalities and institutional diversity to the public health and pandemic debates. The recent pandemic itself is a result of actions taken by actors at multiple scales. For instance, decisions within a household as to what forms of preventative measures to adopt, what sources of information to subscribe to and disseminate, all have small-to-large effects on disease spread and prevention.

Our second contribution is to show that many public health measures, such as social distancing, mask wearing, and self-monitoring and quarantining, require co-production (Rayamajhee et al., 2021; Steen and Brandsen, 2020). That is, inputs from both the providers and the intended beneficiaries (citizens) are needed to produce any amount of output (Parks et al., 1981). Although government can play an important role in promoting the adoption of such measures, they cannot provide them alone. If inputs from the intended beneficiaries (citizens) are absent, governments face extraordinary epistemic challenges in gathering relevant information for policymaking (Pennington, 2020). They also face prohibitive monitoring and sanctioning costs to implement such policies and to ensure broader compliance (Rayamajhee et al., 2021).

This paper argues that governments are far from being the only relevant centers of authority in pandemic policy design and implementation. The 'third sector' or the civil society, and citizens more broadly, play a prominent role in crisis response (Rayamajhee et al., 2020). Community groups, religious associations, and non-profit organizations take on many responsibilities including resolving coordination problems, providing public and private goods, and rebuilding communities. Social entrepreneurs, and religious and civic leaders promote cooperative behavior by setting and anchoring 
expectations and creating conditions for collective action (Chamlee-Wright and Storr, 2009). Thus, diverse non-state actors at different levels that hold significant authority are vital to successful pandemic response. Using documented cases of co-production during the COVID-19 pandemic from different countries, we show that co-production provides a more useful tool with which to study many aspects of public health, including most, if not all, preventative measures. Co-production is consistent with the empirical reality of a multitude of decision-making authorities working in various capacities to overcome pandemic challenges.

Even though pandemics present global scale challenges, decisions and actions taken by actors at all levels - from households to global organizations - determine the trajectory of the pandemic. Analyses based on the assumption of a singular node of authority frequently generate policy recommendations that clash with regional and local priorities. There is no global organization with the authority to design, implement, and enforce uniform policies. All that global health organizations can do is to provide recommendations to its member states. Thus, fighting the pandemic at the global level is handicapped by the lack of global enforcement mechanism. Second, even if the leaders of member states agree on some recommendations, they are likely to face domestic challenges when implementing them. In democratic states, leaders face political opposition that can preclude them from implementing policies that are handed down to them by an external organization. Thus, we advance the notion of polycentricity as a guide to a realistic and empirically consistent theoretical framework with which to analyze pandemic governance.

In section 2, we discuss shortcomings of the social planner approach (SPA) that dominates pandemic policy analyses. Then, we reframe pandemic response as a nested externalities problem and describe the advantages of such reframing. In section 3, we describe public health measures in response to COVID-19 as co-production processes and explore some preliminary evidence. We provide examples of co-production to illustrate the successes and failures of government policies. In section 4, we discuss key institutional implications of reframing pandemic challenges as nested externalities problem and pandemic response as co-production processes. We argue that polycentricity offers a better analytical framework to address these challenges. Section 5 reflects upon the political challenges of encouraging polycentricity and why we usually don't see more polycentric governance of large externalities in practice. Section 6 concludes.

\section{Reframing pandemic governance as a nested externalities problem}

\subsection{Shortcomings of the social planner approach}

A pandemic is 'an outbreak of a disease that occurs over a wide geographic area (such as multiple countries or continents) and typically affects a significant proportion of the population' (Merriam-Webster, 2021). From a strictly epidemiological perspective, a pandemic is a global health crisis. That is, pandemic challenges are primarily viewed as health problems of a global scale, which will require 'combined efforts of all the countries in the world for the epidemic to ultimately subside' (Tu et al., 2020). From an economic perspective, a pandemic is a global externality challenge: infected individuals engage in activities that impose negative externalities such as increased infection risks on those with whom they interact (Bethune and Korinek, 2020). Moreover, non-infected individuals engaging in activities are at an increased risk of getting infected themselves and thus increase risks for others, thereby creating negative externalities. Because market mechanisms and avenues for exchanging property rights to internalize these externalities are absent, economists argue that this provides an adequate justification for government intervention into the social and economic lives of individuals.

Both perspectives - pandemic as a global health crisis and as a global externalities problem - are consistent with the SPA to pandemic response (Alvarez et al., 2020; Gersovitz, 2011; Gersovitz and Hammer, 2004). SPA models consider pandemic response from the view of a benevolent planner with the knowledge, tools, and incentives to act expediently to limit the spread of the virus. The planner, it is assumed, will consider all costs and benefits, and maximize an aggregated social welfare function by implementing optimal control policy instruments such as quarantines, lockdowns, social distancing, and curfews whenever necessary. The rationale for this approach comes from the theory 
of market failure advanced by Pigou (1920). ${ }^{2}$ Because market exchanges and decentralized mechanisms are unable to internalize the external costs incurred by a third party who is not engaged in these exchanges, governments are to intervene to correct market failure and increase social welfare (Medema, 2009). Arrow (1963) was the first to extend these ideas to healthcare. He argued that, when markets fail to provide optimal medical care, non-market institutions (i.e. governments) have to fulfill that gap.

Analyzing pandemic externalities from the lens of a social (health) planner has major shortcomings (Rayamajhee et al., 2021). First, as public choice economists have pointed out, social planners are not (necessarily) benevolent; they could act in their own self-interest. Like all utility-maximizing consumers, central planners and public sector employees face costs and constraints and respond to private and political incentives (Buchanan, 1979; Coyne et al., 2021). Thus, planners and public sector employees allocating public health resources during a pandemic do so in a manner that could reflect their private interests, not public ones (Leeson and Thompson, 2021). Moreover, public health planners work within a set of political institutions which can create incentive challenges. They include budgetary concerns, competition, and conflict among different levels of government, and political interests of public health officials, which may not align with the goal of optimizing public health provision (Coyne et al., 2021). These challenges may, at times, incentivize officials to exaggerate certain aspects of public health concerns whilst downplaying other aspects, thereby resulting in a misalignment of public health policies from their required optimal levels.

The second shortcoming concerns the complexity of pandemic challenges and the limitations of central planning in dealing with complex challenges (Pennington, 2020). Etiological and epidemiological facts of a pathogen are difficult to establish with precision. For instance, while epidemiologists can discern general principles that tell us possible infection patterns, they cannot generate precise estimates (Ormerod, 2020). How the pathogen spreads across the population will depend on a vast number of context-specific factors that scientists and planners cannot access and process. Both formal (legal, political, and economic) and informal (cultural, religious, and social) institutions shape beliefs, attitudes, incentives, and behavior (Bentkowska, 2021). The combinatorial possibility of these institutions is immense, and as a result, people's motivations, aspirations, attitudes, and behaviors are diverse. Therefore, it is not possible to predict with reasonable certainty whether or not a prescribed policy to limit the spread of a pathogen will lead to an intended social behavior in a large jurisdiction (ibid.). Thus, a social (health) planner faces structural challenges in gathering relevant facts and in designing optimal policy solutions.

Third, even if we ignore the aforementioned problems and assume that all the relevant facts are available to the planner and that she is able to determine the optimal policy, the planner operating in the real world faces high, even prohibitive, transaction costs. Rayamajhee et al. (2021) identify several transaction costs that can arise when implementing pandemic policies: exclusion/boundary costs, decision costs, monitoring costs, and sanctioning costs. Exclusion costs are costs of creating boundaries; decision costs are the costs of collective decision-making, monitoring and sanctioning costs are incurred in designing and implementing mechanisms to track violators and punish them. All these costs must be overcome to successfully implement any pandemic policies. This requires efforts from the bottom-up. Without such efforts, these costs can escalate to levels that make implementing a pandemic policy economically unviable (Bentkowska, 2021). Thus, analysts using the SPA to public health are likely to exaggerate the ability of a central planner to implement an optimal pandemic policy from the top-down and underestimate the possibility and consequences of policy blunders.

\subsection{Pandemic governance as a nested externalities problem}

The framework of nested externalities provides a better foundation to analyze large-scale externality problems, including global challenges such as pandemics and climate change (Ostrom, 2009, 2012).

\footnotetext{
${ }^{2}$ For a deeper dive into the intellectual debates on market failure theory, see Medema (2009).
} 
Externalities are said to be nested when 'actions taken within one decision-making unit simultaneously generate costs or benefits for other units organized at different scales' (Ostrom, 2012: 356). Viewed this way, pandemic externalities are a set of nested collective action problems to be overcome by those directly involved, instead of an optimal control puzzle to be solved by experts and implemented by a central planner. Although an analyst may find it convenient to view global challenges as a singular and homogenous problem, many global challenges are, in reality, comprised of numerous heterogeneous externalities nested in multiple levels with significant overlaps between levels (Ostrom, 2009).

Various pandemic challenges, including the limiting of the spread of infectious diseases such as COVID-19, fit well with the above description of a nested externalities problem. The decisions and actions taken to limit the spread of the virus at each jurisdictional level - counties, cities, states, regions, countries, and continents - generate costs and benefits that are transferred to other levels. How individuals, families, schools, and businesses within a jurisdiction respond to the pandemic generates externalities to the neighboring jurisdictions. Similarly, policies adopted by a political unit at a specific jurisdictional level, say a county, matters not only to that unit or level but across other levels. Unlike the standard treatment of pandemic externality as an optimizing problem - to be solved by a singular authority through uniform policies - the framework of nested externalities views the problem as that of solving multilevel collective action problems.

This alternative framing offers several key advantages. First, this approach acknowledges the highly dispersed nodes of interconnected or autonomous authorities that may be beyond the grip of a central planner. Infectious diseases do not obey a political boundary enforced by a jurisdictional authority. In some instances, the scale of externality may be too small for a high-level authority, thereby limiting its ability to create targeted policies to internalize the externality. In other cases, the scale of externality may be too large for the authority to effectively internalize it. Thus, the appropriate jurisdictional level at which to internalize the externality is not fixed. Depending on the organization of administrative and political units, the existing number of levels may be insufficient to match the scale of externality. That is, there are scale gaps. To overcome these gaps, effective coordination of different nodes of authority across administrative and political hierarchies is needed. The SPA ignores the need for coordination.

The second advantage that the nested externalities framework offers is that it accounts for the central role of social capital and informal institutions in solving collective action problems in the context of crises (Ostrom and Ahn, 2008). When pandemic challenges are viewed, not as optimal control puzzles to be solved by an external authority, but as collective action problems to be resolved by those with skin-in-the-game, the role of social capital becomes critical. The disaster literature documents three related channels through which social capital fosters collective action: (1) by establishing norms of compliance, (2) by facilitating transmission of information and knowledge, and (3) by increasing trust (Chamlee-Wright and Storr, 2011; Rayamajhee and Bohara, 2020). The SPA fails to account for these mechanisms because it views these problems from the perspective of an outsider (the expertplanner), who is assumed to possess the social capital - ex nihilo - required to sustain trust and compliance.

The third advantage that the nested externalities framework offers is that it transcends the sterile market-state dichotomy (Ostrom, 2010b). While many on-site pandemic externalities - that is, externalities occurring within a privately owned property or firm - can be addressed by private regulations within the specific site, market mechanisms and private regulations may not fully address cross-site externalities (i.e. externalities with spillover effects to neighboring sites and public spaces) (Leeson and Rouanet, 2021). For instance, infected visitors traveling from one bar to another transport the viruses with them (thus creating externalities along the way), which cannot be fully internalized by the other bar owners because of the virus's long incubation periods. The subsequent bar owners also lack the information (due to problems of information asymmetries) about the visitors' histories and social practices to accurately calculate risks.

On the other hand, for the reasons discussed before, large governments (states) also lack the knowledge and means to internalize externalities from the top down (Ostrom, 2012). With regard to 
pandemic response, government policies meant to guide social behavior are only effective insofar as citizens trust their authorities (Bentkowska, 2021). Without public trust and mechanisms of selfmonitoring in place, governments face prohibitive monitoring and sanctioning costs to implement such policies. Thus, pandemic response involves trust-related social challenges that neither markets nor governments can address fully. Although both markets and the state can play some trust-enhancing role, much of that role falls outside the domain occupied by markets or the state. That is, the static market-state dichotomy is characterized by scope gaps (Ostrom, 2005). Informal and non-state associations, such as churches and clubs, can fill some of these gaps as they have a considerable authority in guiding social behavior (Chamlee-Wright and Storr, 2009, 2011; Rayamajhee et al., 2020). Moreover, solving collective action problems is less difficult when, for instance, church leaders and local media influencers work with government officials and private businesses. The SPA fails to account for the existence and relevance of civil society and informal institutions, and their co-productive interactions with markets and governments (Ostrom, 1990).

In sum, analyzing pandemic externalities as problems of governing nested externalities at different scales allows us to avoid the oversimplification that a global solution must be the only way to cope with global challenges (Ostrom, 2009, 2010a, 2012). The COVID-19 pandemic has made it clear that efforts at all levels (national, regional, and local levels) and across all sectors (private, public, and the 'thirdsector') are needed to address large-scale externality problems. Top-down solutions negotiated at the global or national level, if not backed up by efforts at the lower levels, will not generate sustainable solutions (Ostrom, 2012). Collective action problems vary widely across countries, communities, and cultures. Solutions, therefore, must reflect diverse institutional conditions on the ground (Ostrom, 2005). Despite this reality, scholars continue to overinvest efforts into monocentric ways of articulating the problems we face, thus oversimplifying the nature of complex governance challenges (Thiel et al., 2019). We also showed how the nested externalities framework recognizes that global challenges cannot have a single all-encompassing solution and require efforts from all sectors and across all levels.

\section{Pandemic response as co-production}

\subsection{Co-production and public health}

The concept of co-production was advanced by scholars at the Workshop in Political Theory and Policy analysis at Indiana University (the Workshop) to explain the delivery of local public goods and services (Ostrom et al., 1978; Parks et al., 1981). Elinor Ostrom and her colleagues at the Workshop conducted extensive studies of local public goods delivery in 1970s and concluded that effective delivery was possible only when professional providers and service users proportionately contribute necessary inputs (Ostrom, 1996). Thus, they developed co-production theory to explain the interdependence between the two classes of inputs, which they named regular producer inputs and consumer producer inputs. Co-production theory suggests that certain goods and services require inputs from both regular producers and consumer producers for their production and/or provision (Aligica and Tarko, 2013; Brandsen and Pestoff, 2006; Parks et al., 1981). That is, for the good or service to have any positive value requires a 'mixing of the productive efforts' from both parties (Parks et al., 1981: 1002). Police services, fire protection, education, and healthcare are common examples.

As some public administration scholars have recently noted, the entire public health policy of social distancing and other voluntary preventative measures can be viewed as a 'gigantic co-production project' (e.g. Steen and Brandsen, 2020: 852). Rayamajhee et al. (2021), for instance, argue that no amount of social distancing can be provided by the government alone if inputs from citizens ('the beneficiaries') are missing. Without citizen input, governments face insurmountable epistemic challenges in gathering relevant information and prohibitive monitoring and sanctioning costs in designing and implementing any social distancing policies (Pennington, 2020; Rayamajhee et al., 2021). Moreover, even a benevolent central planner, in the absence of necessary feedback from citizens, faces incentives and tradeoffs that make it prone to make policy errors (Coyne et al., 2021). Thus, theories that do not 
take co-production seriously are likely to generate predictions that overvalue the competence and ability of central governments to gather and act upon vital information and undervalue the probability and consequences of major policy blunders.

\subsection{Co-production and pandemics: empirical observations from the COVID-19 pandemic}

Some scholars describe COVID-19 challenges as 'wicked issues' - defined by high uncertainty, complexity, and severity (Head and Alford, 2015; Steen and Brandsen, 2020). Others describe them as complex phenomena, where 'elements that make up a greater whole do not interact in a linear fashion and where the number of elements and the character of their interaction is too vast for them to be comprehended by scientific observers' (Pennington, 2020: 204). Although expedient and authoritative actions by a central authority may be needed in limited arenas (e.g. Park and Chung, 2021), lasting solutions to 'wicked issues' or 'complex phenomena' such as pandemics must reconcile conflicting value systems and perspectives of multiple parties. Governments thus cannot address complex challenges alone, no matter how efficient their bureaucratic apparatuses are. Citizen inputs are essential in governing pandemic externalities.

Rayamajhee et al. (2021) analyze in depth the co-production of social distancing during the COVID-19 pandemic. They argue that draconian measures such as severe restrictions and lockdowns ignore the co-productive nature of social distancing. Thus, such measures are unlikely to generate long-term success, despite the possibility of short-term uptick in compliance rates. Instead, they emphasize the importance of non-coercive measures such as strengthening existing informal mechanisms for mutual monitoring and sanctioning to encourage long-term cooperation. Such mechanisms better reflect the diversity of value systems and perspectives and are thus better able to generate a shared understanding of risks and mitigation measures. Head and Alford (2015) also argue that a shared understanding of the problem definition and solutions must be generated through discussion and contestation processes. Often, these processes themselves are more important than the details of final policy proposal, as they serve important validation and legitimization roles. An 'optimal' solution generated in an institutional vacuum that bypasses such processes cannot be considered to be validated, regardless of their scientific merit. So, they are unlikely to be accepted widely (Bentkowska, 2021; Ostrom, 2000).

In practice, co-production of public health is ubiquitous during the COVID-19 pandemic, even though economists and social scientists have been slow to acknowledge it. For example, in the United States, both federal and state governments have actively sought public participation and cooperation from non-profit organizations and for-profit businesses in limiting the spread of the virus. Citizens, in turn, have responded by limiting in-person gatherings and finding innovative ways to retain some sense of 'normalcy' during the pandemic. In many instances, community members have adapted their networks to meet new collective needs. There is recent empirical evidence supporting these insights. Storr et al. (2021), for instance, document the formation of socially isolated learning 'pods' in Seattle, Washington to provide kids with in-person instruction and socialization opportunities, whilst also providing a form of local governance amid the pandemic. Within these pods, close-knit families in a local neighborhood come together to share childcare responsibilities so that it reduces burden for individual families while maintaining social distancing and sanitary guidelines. Although the creation of 'pods' are private family-based efforts to minimize costs of services, they complement and benefit from government policies such as public health messaging and social distancing guidelines. Thus, the co-production of social distancing is made possible by private inputs (creation of 'pods') and government inputs (public health messaging and social distancing guidelines).

Shi et al. (2020) study the role of non-profit organizations serving the homeless population in Dallas, Texas during the COVID-19 pandemic. They find that non-profit organizations adopted innovative and creative methods to ensure continuity in service delivery in the face of severe disruptions and ambiguity caused by the pandemic. A Dallas area non-profit that provides shelter to 
individuals experiencing homelessness worked closely with the city of Dallas to overcome housing shortages caused by social distancing mandates. The non-profit reached out to the city government to advise a solution: to open a convention center which remained unused due to a ban on large social events for shelter purposes. The authorities accepted their recommendation. Although the city had the physical infrastructure (the building), they were unable to hire and train professional staff to take care of the population. The non-profit organization stepped in to fulfill that need and helped to provide the needed services. In this case, an effective response was co-produced by a direct mixing of inputs from a non-profit organization (professional staff and management) and government authorities (convention center operated by the city).

Cheng et al. (2020) examine how public sector leaders coordinated with community-based organizations (CBOs) in Zhejiang, China to contain the COVID-19 pandemic. Although the dominant media narrative attributes Zhejiang's success to provincial government's expedient response, CBOs occupied the center stage in the province's COVID-19 response. Over 34,000 CBOs mobilized about 2.8 million volunteers to perform vital tasks such as tracing the source and spread of COVID-19, collecting donations and necessary supplies, assisting businesses to resume production of vital supplies, and preparing and providing meals to those in quarantine. Local governments complemented CBOs efforts by pooling strengths and providing resources to the most affected areas. They also assisted university researchers to obtain resources, technology, and access necessary to generate new knowledge that could inform pandemic response. The authors warn that solely crediting the central government for Zhejiang's success is both dangerous and misleading. They emphasize that the success should be attributed to the ways CBOs worked with local governments to co-produce effective COVID-19 response.

In contrast, Brazil provides an illustrative case where the federal government did not fulfill its co-productive role in COVID-19 response. Instead, Brazilian President Jair Bolsonaro dismissed COVID-19 as a 'gripezinha' (little flu), discouraged the population from getting vaccinated, and launched an attack on the scientific community for communicating about the pandemic (Hallal, 2021). As Ramirez de la Cruz et al. (2020) note, although intermunicipal collaboration was widespread in Brazil, there was a lack of cooperation and support from high-level authorities. It comes as no surprise to many that $345,000^{3}$ Brazilians have died of COVID-19, second only to the United States (Spring and Ricardo, 2021). Brazil, alongside India, has been considered as one of the worst examples of governmental response to the pandemic, where central authorities have deliberately disregarded scientific advice, disseminated false information, and/or withheld data and vital information from scientists and researchers (Nature Editorial, 2021).

Despite national-level policy blunders, there were some successful co-production efforts at the local level in Brazil. Many small municipalities relied on previous partnerships to pull resources to respond to the pandemic. For example, Santa Catarina Inter-federative Consortium (CINCATARINA), a consortium of 109 associated municipalities, created a common platform called PANEL COVID-19 (the panel) to provide support to member municipalities. In response to the dismissive policies and messaging by the federal government, CINCATARINA mobilized the local assets of its member municipalities to disseminate accurate information about the risks and prevention measures based on the available scientific knowledge. The panel facilitated effective communication between public authorities, private businesses, and philanthropic entities to ensure that the products, services, and supplies needed for the prevention and treatment of COVID-19 are readily available. Although there are empirical hurdles to isolating and quantifying the impacts of CINCATARINA's role in limiting the spread of the virus, one noticeable result is an increased collaboration between private suppliers of local agencies to identify people's needs and ensure timely supply (Ramirez de la Cruz et al., 2020).

The documented success stories such as the ones reviewed above almost always entail effective co-production between governments, non-profit organizations, businesses, voluntary associations,

\footnotetext{
${ }^{3}$ Reported on April 8, 2021. With the daily record of about 4,249 deaths, this number is likely to rise by the time of publication.
} 
and private citizens. The corollary is also worth emphasizing: governance failures can be attributed, at least in part, to the lack of complementarity between government policies and citizens' efforts and to the disregard for institutional diversity and informal institutions (Bentkowska, 2021; Rayamajhee et al., 2021). Although co-production does not guarantee success, as evident in Brazil, its absence or disregard, certainly leads to failure. Where governance efforts by voluntary associations, local authorities, and the scientific community are met with hostility and dismissal by central authorities, devastation and tragedy are likely to follow (Ostrom, 1990).

\subsection{Conditions for successful co-production: Complementarity of inputs for co-governance}

In evaluating the conditions necessary for successful citizen co-production to occur, it is important to consider the type of relationships between inputs from the two co-producers - citizens and governments. Co-production is feasible when either of the two types of relationships exist between regular producer inputs and consumer producer inputs: substitutable and complementary (Aligica and Tarko, 2013; Parks et al., 1981). The two classes of inputs are said to be substitutable if a one unit of regular producer input (with marginal productivity $a$ ) can be replaced by an $a / b$ unit of consumer producer input (with marginal productivity $b$ ) without affecting the quantity of output produced. For example, residential garbage collection is a service (output) where the inputs from households and municipal garbage collection agency are substitutable. A resident may choose to not accept the service from the agency and instead take garbage to the drop site herself. This will require replacing all regular producer inputs with consumer producer inputs. However, the inputs are said to be complementary, or interdependent, when no output can be produced without both types of inputs. The production of education is an example where inputs from both teacher and student are essential (Parks et al., 1981).

In the case of pandemic governance, many preventative measures including social distancing require both substitutive and complementary inputs from providers (governments) and beneficiaries (citizens) (Rayamajhee et al., 2021). In theory, social distancing can be produced by citizens alone, whereas governments, no matter how efficient their bureaucratic apparatuses are, cannot produce it alone. In practice, however, social distancing may require a mixing of both government and citizen inputs (Steen and Brandsen, 2020). That is because, for social distancing to have any tangible effect in limiting the spread of the virus requires solving collective action problems at different levels. This in turn requires an effective coordinating and information-dissemination role, which can be provided by governments. Thus, successful co-production of many preventative measures during a pandemic requires complementarity of co-producer inputs.

The role of social capital and public trust is also pivotal to ensuring complementarity between government and citizen inputs. For instance, as Rayamajhee et al. (2021) note in their analysis of social distancing, strong social capital allows for mechanisms of mutual monitoring and sanctioning to co-exist with government policies. Moreover, where public trust is high, citizens can form reliable expectations that government officials will reciprocate and complement citizen inputs. In an institutional environment characterized by high social capital and public trust, individuals, families, local communities, and businesses can foster new forms of social capital or dynamically reconfigure old forms of social capital to overcome new collective dilemmas (Storr et al., 2021). Local governments can thus provide complementary inputs by validating informal mechanisms and coordinating with higher level government authorities (Ostrom, 2000).

However, where social capital is weak and self-commitment is lacking, costs of monitoring and sanctioning can rise to prohibitive levels (Ostrom, 1990). This can provide justification for the role of government to impose measures to ensure compliance, given that the costs of non-compliance spill over to neighboring territories. Even when such measures are unavoidable, the type of inputs governments use to fulfill this role are critical. If government inputs comprise of stringent measures such as military intervention, mass surveillance, and harsh penalties, - i.e. inputs that are substitutes for informal mechanisms of mutual monitoring and sanctioning - they can crowd out or displace voluntary efforts in the long run (Ostrom, 2000). Even in the short run, such measures can exacerbate pandemic denialism and vaccine skepticism. These 
challenges cannot be sustainably addressed by using draconian methods. Instead, focus should be directed toward increasing public trust and fighting misinformation through trusted channels.

If governments employ measures that are complementary to citizen engagement - such as compiling and disseminating accurate information and providing reliable public health guidelines based on the available knowledge - they are likely to increase long-term compliance rates and complement the efforts of informal institutions (Bentkowska, 2021). To conclude, the concept of co-production provides a more useful tool with which to study many aspects of pandemic governance, including most, if not all, preventative measures. The concept is particularly relevant for studying pandemic response in democratic regimes, where nodes of authorities are dispersed, and citizens possess certain inalienable rights and autonomy.

\section{Implications for institutional analysis: toward a polycentric approach}

Interpreting a pandemic as a nested externalities challenge and pandemic responses as co-production processes has some direct implications for policy analysis. First, because many pandemic responses comprise of private efforts by citizens, businesses, independent organizations, and informal associations, policy analysts must consider the role of non-governmental actors and informal institutions in pandemic response. This entails viewing many aspects of pandemic response as emergent and cooperative phenomena with dispersed nodes of authorities. Although governments play a pivotal informative and catalytic role in pandemic response, they are far from being the only relevant actors for pandemic policy design and implementation. Therefore, analysts must account for all other relevant actors who participate in pandemic response in various capacities. This means taking institutional diversity and non-market decision-making seriously in the analysis of pandemic governance.

Second, policy analysts must evaluate whether a given government policy complements or crowds outs co-production efforts by non-governmental actors at the microlevel. Local actors, both governmental and non-governmental, are better equipped with the knowledge, tools, and community ties to design and implement policies that address local idiosyncrasies (Ostrom, 1990; Rayamajhee et al., 2020). Uniform solutions from the top down simply cannot motivate the same level of trust and complementarity and may instead crowd out citizens' involvement at the local level (Ostrom, 2000). Such solutions, even those with scientific merit, are likely to be deemed illegitimate, resulting in non-compliance, or worse, resentment and retaliation (Rayamajhee et al., 2021). Moreover, analysts must also consider how policies by the central government influence incentives for local governmental actors. Local governments may be less willing to expend their limited resources when they expect higher level authorities to intervene. Worse yet, top-down efforts, if perceived as coercive, can engender retaliatory or perverse effects at the lower levels.

Third, analysts must consider institutional adaptability and flexibility as key policy evaluation criteria. A pandemic situation is in the state of constant flux. Hotspots change over time and across geographical areas. City A could have low case counts at the same time when City X is experiencing an outbreak. Therefore, policy analysts must consider whether a given policy allows non-governmental and local governmental actors to adopt flexible strategies that account for differences in severity and economic tradeoffs across locations and overtime. Moreover, if the only policy adopted is at the national or global scale, citizens, firms, and organizations in distant places will have a hard time trusting that their interests are adequately considered. It is unlikely that a small group of expertplanners can account for diverse interests. Thus, in evaluating a given policy intended to limit the spread of pathogens, an analyst must consider how well a given policy allows stakeholders to adjust their strategies to address evolving challenges.

Finally, although the focus of this paper is on the policy analysis and institutional framework rather than the specifics of the policy itself, our characterization of pandemic challenges as multi-level nested externalities problems means that there is no single enforcement mechanism to combat the pandemic. In other words, there is no panacea (Ostrom, 2005). Pandemic policy design and enforcement thus require configural approaches to overcome different transaction costs and match diverse context- 
specific challenges across the nested levels. Consider exclusion/boundary costs involved in enforcing pandemic policies (Rayamajhee et al., 2021).

The extent to which citizens trust their political institutions is critical to determining the appropriate enforcement boundaries and estimating boundary costs. For example, if national or provincial authorities are unable to garner enough citizen trust needed to effectively enforce social distancing measures, policymakers must explore configural approaches that empower local governments, nonstate actors, or private enterprises to minimize boundary costs. If informal institutional solutions by church organizations and civic associations are better equipped to promote public trust and encourage citizen participation, their jurisdictions are more relevant to analyzing and enforcing pandemic policies. ${ }^{4}$ Hence, the major takeaway is that policy analyses built on the presumption of a singular node of authority are likely to derive policy recommendations that do not match the scale and the complexity of the externality they aim to internalize or the collective action problems they intend to resolve (Ostrom, 2010a). A more decentralized, polycentric, and adjustable policy framework that does not assume away diversity and heterogeneity is warranted.

\subsection{Toward a polycentric approach to pandemic governance}

A polycentric approach to policy analysis offers an alternative analytical framework that accounts for both the nestedness of externalities and co-production processes - features that are characteristic of the real world, but typically ignored by scholars (Ostrom, 2005). It is important to distinguish between a polycentric system and a polycentric approach to policy analysis. A system of governmental units is said to be polycentric if it comprises of numerous independent decision-making centers that may enter into formal and informal contractual relationships to achieve specific goals (Ostrom et al., 1961). A variety of governance types can be considered as being polycentric (Thiel et al., 2019). Even a strictly hierarchical system usually comprises of parts that have some polycentric features. Whereas, polycentric analysis refers to examining governance situations through the lens of polycentricity - that is, polycentric analysis means 'seeing polycentrically' (Blomquist and Schröder, 2019).

Unlike the hierarchical approach commonly adopted in pandemic policy analyses, the polycentric approach accounts for the nestedness of pandemic externalities within multiple governmental units. Each governmental unit at the micro- and meso-levels must take into account the challenges facing other governmental units (across micro-, meso-, and macro-levels) and the policies and actions they adopt. Thus, when analyzing policies from a polycentric perspective, relationships between governmental units - competitive, cooperative, or mixed - become pivotal. Accounting for these relationships is crucial because decisions made in real world, especially those pertaining to infectious disease externalities, do not occur in isolation. Moreover, private enterprises, government agencies, and nonprofit organizations often operate across different governmental jurisdictions and share overlapping goals (Ostrom et al., 1961). Through these overlapping roles, they develop experience, expertise, and partnerships that can be crucial in pandemic response. Contrary to the Pigouvian SPA, the polycentric framework offers enough flexibility to incorporate these overlapping roles and relationships.

Another advantage that the polycentric framework offers is the flexibility of the level of analysis (Ostrom, 2005). Pandemic externalities vary widely in types and scales. Higher rates of infection, deaths, and hospitalizations in one location can affect neighboring locations. Reduction in business operations and government revenue in one jurisdiction also affects neighboring jurisdictions. Media reaction to pandemics in a specific area can affect other areas. But the scale of each of these externalities will likely be different. For instance, economic externalities can be more geographically limited than epidemiological externalities, at least in the short run. Moreover, the scale of the externality depends largely on where groups or cities are on the infection curve, which changes continuously (Küchenhoff et al., 2021).

\footnotetext{
${ }^{4}$ To see at depth possible bottom-up enforcement and monitoring mechanisms amid a pandemic consult: Leeson and Rouanet (2021), Storr et al. (2021), and Cai et al. (2021).
} 
Thus, the unit at which the externality can be optimally internalized is likely to vary depending on the specific externality being considered and its scale at a given time (Ostrom et al., 1961). An analyst focusing on a fixed level to design policies will thus come up with rigid recommendations that either do too much or do too little. On the other hand, an analyst using the polycentric approach is not tied to a specific level of analysis. In fact, one of the central strengths of the polycentric approach is that it allows a researcher to zoom-in or zoom-out to different levels depending on the scale of externalities and the dynamics of existing formal and informal institutions (Ostrom, 2005). ${ }^{5}$ By regularly revising and adjusting the level of analysis, the analyst is likely to generate more nuanced policy recommendations that better match the scale of externality at hand and better fit the challenges facing communities on the ground.

\subsection{Institutional fragilities and polycentricity}

Scholars have noted that the lack of effective central authority can pose coordination challenges and management problems that add difficulties in implementing health policies, particularly in fragile states (Lieberman, 2011). Additionally, when nation states lack legitimacy and contract enforcement mechanisms are weak, contracting parties (governmental and non-governmental actors and agencies) do not have a recourse to address a breach in an agreement. That can lead to contract breakdown situations where exchange relationships cannot function (Williamson, 2002). In such cases, an outside entity such as a donor agency may find polycentric approach to be more burdensome than direct top-down intervention (Lieberman, 2011). Moreover, the presence of overlapping roles can incentivize government actors to free ride on the efforts of non-governmental actors or blame them for inefficiencies and failures. This is particularly problematic in developing counties with less accountable political systems, but it can also generate substantial costs in societies that have better state capacities.

A multitude of governance regimes qualify as polycentric (Blomquist and Schröder, 2019). Even totalitarian systems incorporate many polycentric features such as overlapping, semi-autonomous internal policing for the purpose of strengthening the central authority's political power (Thiel et al., 2019). It comes as no surprise, therefore, that polycentricity characterizes the governance of infectious diseases in many countries, including those that handle infectious diseases poorly (Lieberman, 2011). We leave aside the normative and economic rationale for advancing polycentric systems to other scholars (see Thiel et al., 2019). However, given that governance regimes with multiple, semi-autonomous nodes of authority with overlapping roles are ubiquitous, we argue that pandemic policy analysis should take polycentricity seriously.

Ultimately, analyzing pandemic challenges polycentrically does not mean simply classifying a given system as more or less polycentric with the goal of recommending more or less polycentric governance to address a given challenge (Blomquist and Schröder, 2019). Polycentric order emerges; it cannot be planned or replicated based on an a priori design (ibid.: 45). Polycentricity thus presents an analyst with constraints she must work with: it is not a mechanical lever she can manipulate to achieve specific policy goals (Ostrom, 1990). Thus, instead of deriving an abstract model of polycentricity from which to empirically analyze a case, the analyst must consider carefully different decision-making centers, their functions, capacities, and overlaps, their relationships (interdependent or independent, formal or informal) and histories, and various ways in which different centers coordinate (Blomquist and Schröder, 2019: 46-56). Policies that ignore these features are sure to encounter frictions, higher decision costs, scale-mismatches, and delays during implementation. This partly explains why external agencies including global-health organizations often experience unexpected difficulties in implementing policies to control the spread of infectious diseases.

\footnotetext{
${ }^{5}$ The Institutional Analysis and Development (IAD) framework can be used for this purpose (Ostrom, 2005: chapters 1 and 2).
} 


\section{Why do we not see more polycentric governance in practice?}

Even though pandemic governance can be provided more efficiently through a polycentric approach, consolidationist tendencies dominate public discourse and policymaking (Bagus et al., 2021; Gleißner et al., 2021; Leeson and Thompson, 2021). Given this discrepancy, it is important to reflect on possible reasons as to why we observe pressures from governments and the public alike to implement monocentric policy solutions.

One plausible explanation is that the urgency and scale of pandemic challenges incentivize policymakers and the public to seek for a singular expedient solution - deus ex machina to make the crisis go away at once. This temptation leads policymakers to propose simple, monocentric solutions to complex problems (Ostrom, 2010a). As Ostrom (2012) notes, policymakers, particularly in the higher echelons of governments, tend to conceptualize large-scale externalities in a simple way and assume that they are homogeneous and global (or national). Concomitantly, scholars investigating and advocating for monocentric solutions provide scientific validation and public justification to implement consolidationist policies. They argue that consolidation removes redundancy and expedites efficient solutions (Ostrom et al., 1961). Gleißner et al. (2021) report that a similar rationale was used to advocate for centralization of vaccine procurement and distribution in the European Union (EU). A popular argument was that the EU, as a singular organization rather than dispersed individual nations, would be in a better negotiating position and would be able to distribute vaccines more efficiently. In reality, however, centralization led to immense coordination challenges, bad policy decisions, misallocations, and poor vaccine supply in Germany, as well as other logistic problems (ibid.:10).

A second reason is that policymakers and public health professionals could be motivated by private interests, not public ones (Coyne et al., 2021; Leeson and Thompson, 2021). Public choice literature on public health points out that agents in the public sector find it beneficial to maximize the domain of the public health sector and increase control of public health resources (Daumann and Follert, 2020; Leeson and Thompson, 2021). The polycentric approach entails rescinding of central control of public health resources, which is inconsistent with the private interests of public officials individually and public departments as a collective that stand to benefit from consolidation. Moreover, various interest groups seeking rents for their members engage in lobbying efforts to influence political actors to increase public spending, which results in more public spending and consolidation of the public health sector (Daumann and Follert, 2020). Thus, strong institutional and political pressures toward monocentric control of public health resources exist, which can undermine polycentric solutions.

Moreover, two polar predispositions are pervasive during a pandemic, both of which present additional hurdles to polycentric governance. On the one end of the spectrum, pandemic denialism and vaccine skepticism are widespread. Those in favor of consolidation thus claim that decentralized alternatives are idealistic when a significant subpopulation is in denial. On the other end of the spectrum are those engulfed in mass hysteria (Bagus et al., 2021). A relevant facet could be related with the 'political economy of mass hysteria' in the face of opacity and health uncertainty (ibid.). Mass and social media allow threats to be exaggerated and transmitted across populations, thus creating a strong demand for swift and forceful action by central governments to squelch any perceived threat. Thus, it is plausible that mass hysteria, exacerbated by digital platforms and polarized mass media, could lead to policy failures which persistently favored top-down and centralist solutions. Policymakers who push for immediate action are favored over those who advocate for deliberative policy decisions, even though the former is more likely to result in policy blunders and adverse consequences. Consequently, polycentric governance faces significant resistance from the public and their representatives alike.

\section{Concluding remarks}

The scope of this paper has been to point out an alternative-institutionalist way forward to intellectually grapple with pandemics as nested externalities. The approach we put forth in this essay recognizes that one cannot design an optimal system in advance and make it work for complex externality 
challenges that change from one moment to another. We showed that pandemics present nested externalities challenges that require multilevel solutions by a wide variety of actors endowed with different strengths and resources. Pandemic challenges manifest differently across different sub-populations and interact with existing social and economic problems, taking even diverse forms. The Pigouvian public policy enacted by a single governing authority for an entire nation imposes fixed problem definitions and institutionally rigid assumptions to issues that require heterogeneous and nested solutions. Thus, it has the effect of generating policy mismatches and inefficiencies due to the rigidities imposed from the top down. Moreover, imposing fixed and large-scale solutions to nested problems can engender a sense of illegitimacy, which results in citizens' outrage and retaliation in the form of non-compliance, protests, and civil unrest.

Rules designed by communities and actions led by members of the same communities are more likely to succeed in cultivating co-production than rules and initiatives by outsiders (Ostrom, 2000). Because it is crucial to get locals to participate in governance efforts to contain the spread of the virus, the net effect of a policy enacted to motivate social behavior conducive to virus containment depends upon how well it incentivizes cooperation between officials and citizens. Since this kind of cooperation will be easiest among groups with strong social ties, policies that are built on social capital are more likely to address local challenges than measures implemented from the top down (Rayamajhee, 2020; Rayamajhee and Bohara, 2020; Rayamajhee and Paniagua, 2021).

Thus, the relevant governmental or administrative level for policy analysis is where co-production is technically feasible and economically efficient; that is, where inputs from governments combined with inputs from citizens can lead to effective policy design and cost-effective implementation. This level is likely to vary widely depending on the nature of collective action problems at hand and context-specific factors. Thus, the Pigouvian SPA cannot justifiably incorporate the notion of co-production in policy analysis because it presumes a static national of global level of analysis for welfare maximization whereas co-production is inherently heterogeneous and dynamic. What we have attempted to establish is that pandemic policy analysis requires an adaptive framework that is not tied to a rigid level of analysis.

To conclude, this article has pointed that a productive way forward toward governing pandemics and other global externalities is to move away from Pigouvian models of optimal policy calculation - based on false assumptions about the role of actors at the lower levels - and instead invest intellectual efforts toward polycentric analyses that take co-production and institutional diversity seriously. To generalize more broadly, the central goal of public policies should be, in Elinor Ostrom's words, 'to facilitate the development of institutions that bring out the best in humans' (Ostrom, 2010b). Thus, policy researchers investigating pandemic governance should ask how diverse, polycentric institutions operating at multiple scales can learn from their diverse and shared experiences, adapt to new challenges, innovate, and achieve sustainable outcomes for themselves. We have indicated that this novel institutional research agenda for analyzing large-scale externalities is worth pursuing.

\section{References}

Aligica, P. D. and V. Tarko (2013), ‘Co-production, Polycentricity, and Value Heterogeneity: The Ostroms' Public Choice Institutionalism Revisited’, American Political Science Review, 107(4): 726-741.

Alvarez, F. E., D. Argente and F. Lippi (2020), 'A Simple Planning Problem for COVID-19 Lockdown', NBER Working Paper, No. 26981.

Arrow, K. J. (1963), 'Uncertainty and the Welfare Economics of Medical Care', American Economic Review, 53(5): 941-973.

Bagus, P., J. A. Peña-Ramos and A. Sánchez-Bayón (2021), 'COVID-19 and the Political Economy of Mass Hysteria', International Journal of Environmental Research and Public Health, 18(4): 1376.

Bentkowska, K. (2021), 'Response to Governmental COVID-19 Restrictions: The Role of Informal Institutions', Journal of Institutional Economics, 17(5): 729-745.

Bethune, Z. A. and A. Korinek (2020). 'Covid-19 Infection Externalities: Trading Off Lives vs. Livelihoods', NBER Working Paper, No. 27009.

Blomquist, W. A. and N. J. S. Schröder (2019), 'Seeing Polycentrically: Examining Governance Situations Using a Polycentricity Lens', in A. Thiel, D. E. Garrick, and W. A. Blomquist (eds), Governing Complexity: Analyzing and Applying Polycentricity, Cambridge: Cambridge University Press, pp. 45-64. 
Brandsen, T. and V. Pestoff (2006), 'Co-production, the Third Sector and the Delivery of Public Services: An Introduction', Public Management Review, 8(4): 493-501.

Brown, G. and D. Susskind (2020), 'International Cooperation During the COVID-19 Pandemic', Oxford Review of Economic Policy, 36(S1): S64-S76.

Buchanan, J. M. (1979), 'Politics Without Romance: A Sketch of Positive Public Choice Theory and its Normative Implications', IHS Journal, Zeitschrift des Instituts für Höhere Studien-Wien, 3: B1-B11.

Cai, Q., A. Okada, B. G. Jeong and S.-J. Kim (2021), 'Civil Society Responses to the COVID-19 Pandemic: A Comparative Study of China, Japan, and South Korea', China Review, 21(1): 107-138.

Chamlee-Wright, E. and V. H. Storr (2009), 'Club Goods and Post-Disaster Community Return', Rationality and Society, 21(4): 429-458.

Chamlee-Wright, E. and V. H. Storr (2011), 'Social Capital, Lobbying and Community-Based Interest Groups', Public Choice, 149(1): 167-185.

Cheng, Y., J. Yu, Y. Shen and B. Huang (2020), 'Coproducing Responses to COVID-19 with Community-Based Organizations: Lessons from Zhejiang Province, China', Public Administration Review, 80(5): 866-873.

Choutagunta, A., G. P. Manish and S. Rajagopalan (2021), 'Battling COVID-19 with Dysfunctional Federalism: Lessons from India', Southern Economic Journal, 87(4): 1267-1299.

Coyne, C. J., T. K. Duncan and A. Hall (2021), 'The Political Economy of State Responses to Infectious Disease', Southern Economic Journal, 87(4): 1119-1137.

Daumann, F. and F. Follert (2020), 'COVID-19 and Rent-Seeking Competition: Some Insights from Germany', New Perspectives on Political Economy, 16(1-2): 52-69.

Gersovitz, M. (2011), 'The Economics of Infection Control', Annual Review of Resource Economics, 3(1): 277-296.

Gersovitz, M. and J. S. Hammer (2004), 'The Economical Control of Infectious Diseases', The Economic Journal, 114(492): 1-27.

Gleißner, W., F. Follert, F. Daumann and F. Leibbrand (2021), 'EU's Ordering of COVID-19 Vaccine Doses: Political Decision-Making under Uncertainty', International Journal of Environmental Research and Public Health, 18(4): 2169.

Hallal, P. C. (2021), 'SOS Brazil: Science Under Attack', The Lancet, 397(10272): 373-374.

Head, B. W. and J. Alford (2015), 'Wicked Problems: Implications for Public Policy and Management', Administration \& Society, 47(6): 711-739.

Hodgson, G. M. (2013), 'Editorial Introduction to the Elinor Ostrom Memorial Issue', Journal of Institutional Economics, 9(4): 381-385.

Küchenhoff, H., F. Günther, M. Höhle and A. Bender (2021), 'Analysis of the Early COVID-19 Epidemic Curve in Germany by Regression Models with Change Points', Epidemiology \& Infection, 149(E68): 1-7.

Leeson, P. T. and L. Rouanet (2021), 'Externality and COVID-19', Southern Economic Journal, 87(4): 1107-1118.

Leeson, P. T. and H. A. Thompson (2021), 'Public Choice and Public Health', Public Choice, forthcoming, doi: https://doi.org/ 10.1007/s11127-021-00900-2.

Lieberman, E. S. (2011), 'The Perils of Polycentric Governance of Infectious Disease in South Africa', Social Science \& Medicine, 73(5): 676-684.

Medema, S. G. (2009), The Hesitant Hand: Taming Self-Interest in the History of Economic Ideas, Princeton: Princeton University Press.

Merriam-Webster (2021), 'Pandemic'. [Online] Available https:/www.merriam-webster.com/dictionary/pandemic [2021 Apr. 23].

Nature Editorial (2021), 'India, Brazil and the Human Cost of Sidelining Science', Nature, 593: 7-8.

Ormerod, P. (2020), Model Behaviour, London: Institute of Economic Affairs.

Ostrom, E. (1990), Governing the Commons, Cambridge: Cambridge University Press.

Ostrom, E. (1996), 'Crossing the Great Divide: Coproduction, Synergy, and Development', World Development, 24(6): $1073-1087$.

Ostrom, E. (2000), 'Crowding out Citizenship', Scandinavian Political Studies, 23(1): 3-16.

Ostrom, E. (2005), Understanding Institutional Diversity, Princeton: Princeton University Press.

Ostrom, E. (2009), 'A Polycentric Approach for Coping with Climate Change', Policy Research Working Paper, No. 5095, Washington, D.C.: The World Bank.

Ostrom, E. (2010a), 'Polycentric Systems for Coping with Collective Action and Global Environmental Change', Global Environmental Change, 20(4): 550-557.

Ostrom, E. (2010b), 'Beyond Markets and States: Polycentric Governance of Complex Economic Systems', American Economic Review, 100(3): 641-672.

Ostrom, E. (2012), 'Nested Externalities and Polycentric Institutions: Must We Wait for Global Solutions to Climate Change Before Taking Actions at Other Scales?', Economic Theory, 49(1): 353-369.

Ostrom, E. and T. K. Ahn (2008), 'The Meaning of Social Capital and Its Link to Collective Action', in G. T. Svendsen and G. L. Svendsen (eds), Handbook on Social Capital, Northampton, MA: Edward Elgar, pp. 17-35.

Ostrom, E. and R. B. Parks (1999), 'Neither Gargantua nor the Land of Lilliputs: Conjectures on Mixed Systems of Metropolitan Organization', in M. D. McGinnis (ed), Polycentricity and Local Public Economies, Michigan-Ann Arbor: University of Michigan Press, pp. 284-305.

Ostrom, V., C. M. Tiebout and R. Warren (1961), 'The Organization of Government in Metropolitan Areas: A Theoretical Inquiry', American Political Science Review, 55(4): 831-842. 
Ostrom, E., R. B. Parks, G. P. Whitaker and S. L. Percy (1978), 'The Public Service Production Process: A Framework for Analyzing Police Services', Policy Studies Journal, 7(1): 381-389.

Park, J. and E. Chung (2021), 'Learning from Past Pandemic Governance: Early Response and Public-Private Partnerships in Testing of COVID-19 in South Korea', World Development, 137: 105198, doi: https://doi.org/10.1016/j.worlddev.2020. 105198.

Parks, R. B., P. C. Baker, L. Kiser, R. Oakerson, E. Ostrom, V. Ostrom, S. L. Percy, M. B. Vandivort, G. P. Whitaker and R. Wilson (1981), 'Consumers as Coproducers of Public Services: Some Economic and Institutional Considerations', Policy Studies Journal, 9(7): 1001-1011.

Pennington, M. (2020), 'Hayek on Complexity, Uncertainty and Pandemic Response', The Review of Austrian Economics, 34(1): 203-220.

Pigou, A. C. (1920), The Economics of Welfare, London: Macmillan.

Ramirez de la Cruz, E. E., E. J. Grin, P. Sanabria-Pulido, D. Cravacuore and A. Orellana (2020), 'The Transaction Costs of Government Responses to the COVID-19 Emergency in Latin America', Public Administration Review, 80(4): 683-695.

Rayamajhee, V. (2020), 'On the Dynamic Nature of Goods: Applications in Post-disaster Contexts', in P. Boettke, R. Herzberg, and B. Kogelmann (eds), Exploring The Political Economy and Social Philosophy of Vincent and Elinor Ostrom, London: Rowman \& Littlefield Publishers, pp. 3-30.

Rayamajhee, V. and A. K. Bohara (2020), 'Social Capital, Trust, and Collective Action in Post-Earthquake Nepal', Natural Hazards, 105(2): 1491-1519.

Rayamajhee, V. and P. Paniagua (2021), 'The Ostroms and the Contestable Nature of Goods: Beyond Taxonomies and Toward Institutional Polycentricity', Journal of Institutional Economics, 17(1): 71-89.

Rayamajhee, V., S. Shrestha and P. Paniagua (2021), 'Governing Nested Externalities During a Pandemic: Social Distancing as a Coproduction Problem', Cosmos and Taxis, 9(5-6): 64-80.

Rayamajhee, V., V. H. Storr and A. K. Bohara (2020), 'Social Entrepreneurship, Co-Production, and Post-Disaster Recovery', Disasters, doi: https://doi.org/10.1111/disa.12454.

Shi, Y., H. S. Jang, L. Keyes and L. Dicke (2020), 'Nonprofit Service Continuity and Responses in the Pandemic: Disruptions, Ambiguity, Innovation, and Challenges', Public Administration Review, 80(5): 874-879.

Spring, J. and B. Ricardo (2021), 'Brazil Sets Record Daily COVID-19 Death Toll, Senate to Probe Bolsonaro Government's Response', Reuters. [Online] Available https://www.reuters.com/article/us-health-coronavirus-brazil-idUSKBN2BV38Z [2021 Apr. 21].

Steen, T. and T. Brandsen (2020), 'Coproduction during and after the COVID-19 Pandemic: Will It Last?', Public Administration Review, 80(5): 851-855.

Storr, V. H., S. Haeffele, L. E. Grube and J. K. Lofthouse (2021), 'Crisis as a Source of Social Capital: Adaptation and Formation of Social Capital during the COVID-19 Pandemic', Cosmos and Taxis, 9(5-6): 94-108.

Thiel, A., D. E. Garrick and W. A. Blomquist (2019), Governing Complexity: Analyzing and Applying Polycentricity, Cambridge: Cambridge University Press.

Tu, H., S. Tu, S. Gao, A. Shao and J. Sheng (2020), 'Current Epidemiological and Clinical Features of COVID-19; a Global Perspective from China', Journal of Infection, 81(1): 1-9.

UN News (2020), 'Global Cooperation Is Our Only Choice Against COVID-19, Says WHO Chief, [Online] Available https:// news.un.org/en/story/2020/08/1069702 [2021 May 16].

Williamson, O. E. (2002), 'The Theory of the Firm as Governance Structure: From Choice to Contract', Journal of Economic Perspectives, 16(3): 171-195.

Woodward, D. and R. Smith (2003), 'Global Public Goods for Health: Concepts and Issues', in R. Smith, R. Beaglehole, N. Drager and D. Woodward (eds), Global Public Goods for Health: A Health Economic and Public Health Perspective, Oxford: Oxford University Press, pp. 3-29.

Cite this article: Paniagua P, Rayamajhee V (2022). A polycentric approach for pandemic governance: nested externalities and co-production challenges. Journal of Institutional Economics 18, 537-552. https://doi.org/10.1017/S1744137421000795 